\title{
Integrating a Systemic Paradigm When Treating Combat Veterans with PTSD
}

\section{Adam Clayton Jones* and Rebecca Lucero}

Rawls College of Business, Texas Tech University, Lubbock, Texas Area, USA

"Corresponding author: Adam Clayton Jones, Rawls College of Business, Texas Tech University, Lubbock, Texas Area, USA, Tel: +8067422011; E-mail: adam.jones@ttu.edu

Rec date: September 01, 2017; Acc date: September 22, 2017; Pub date: September 25, 2017

Copyright: (c) 2017 Jones AC, et al. This is an open-access article distributed under the terms of the creative commons attribution license, which permits unrestricted use, distribution, and reproduction in any medium, provided the original author and source are credited.

\section{Commentary}

Following their military service, as many as one-third of military veterans experience, PTSD from exposure to traumatic events associated with war (USA Department of Veterans Affairs (USDVA), 2016). In this commentary, the authors discuss the potential benefits of integrating systemic therapy in the treatment of PTSD in combat veterans.

Following their military service, as many as one-third of military veterans experience PTSD from exposure to traumatic events associated with war [1]. Many of these servicemen and women experience significant difficulty integrating their competing military identity with their civilian identity after returning home [2].

The struggle to resolve competing identities combined with the potentially devastating effects of PTSD symptoms can cause significant distress for the veteran $[2,3]$. However, often times, family members of combat veterans silently suffer alongside the veteran, unsure of how best to help their struggling family member [4].

Despite these unseen effects on family members, the USDVA currently endorses individual treatment models such as traumafocused cognitive behavioral therapy, exposure therapy, and eye movement desensitization and reprocessing (EMDR) [1].

While family therapy is among the treatment options suggested by the USDVA, no systemic models are currently endorsed [5]. Furthermore, combat veterans may have limited opportunities to receive family therapy as licensed marriage and family therapists comprise only $0.7 \%$ of all veteran hospital clinicians [6].

Under the current medical model, many veterans do not seek out mental health services, even when experiencing severe distress due to PTSD $[7,8]$. Combat veterans often fear the stigma associated with receiving a mental health diagnosis [9]. While veterans recognize the difficulties, they experience due to PTSD, they often resist being labeled as mentally weak [10]. In order to better serve this population, it is critical that mental health professionals consider new approaches to provide a less-stigmatizing environment and increase the likelihood of treating the many veterans and families who suffer.

Systemic family therapy offers a new approach in treating PTSD as it differs from other treatments currently offered to combat veterans. Rather than conceptualizing symptoms as a result of individual pathology, family therapists recognize the various contextual factors that contribute to the manifestation of symptoms [11].

Family therapy models focus less on the individual's struggle with PTSD symptoms and instead focus on collaboratively fostering safety, understanding, support, and accountability for all family members [12]. Individual therapies often ignore the ways in which family members may exacerbate or alleviate symptoms of PTSD experienced by the combat veteran. Recent evidence suggests that integrating family members into therapy may lead to quicker, and more costeffective, treatment results than individual treatments [13].

In the presence of complex trauma, individual treatments may certainly be needed; however, systemic therapists conceptualize cases by focusing on contextual factors that will best contribute to treatment success.

In a recent article, by Lucero et al. in 2017 outline the treatment of PTSD in combat veterans using Internal Family Systems (IFS), a systemic therapeutic model. The authors demonstrate how systemic therapy provides a less-pathologizing stance while treating both the individual and relational effects of PTSD.

We encourage clinicians everywhere to consider the many potential benefits of integrating family therapy into the practice of treating combat veterans with PTSD. Doing so may increase the likelihood of helping many veterans and their families whose suffering often goes unnoticed.

\section{References}

1. United States Department of Veterans Affairs (2016) Treatment. PTSD, USA.

2. Smith RT, True G (2014) Warring identities: Identity conflict and the mental distress of American veterans of the wars in Iraq and Afghanistan. Soc Ment Health 4: 147-161.

3. Warner CH, Appenzeller GN, Warner C, Grieger T (2009) Psychological effects of deployments on military families. Psychiatr Ann 39: 56-63.

4. Gorman LA, Blow AJ, Ames BD, Reed PL (2011) National guard families after combat: Mental health, use of mental health services, and perceived treatment barriers. Psychiatr Serv 62: 28-34.

5. Mansfield AJ, Kaufman JS, Marshall SW, Gaynes BN, Morrissey JP, et al. (2010) Deployment and the use of mental health services among US Army wives. N Engl J Med 362: 101-109.

6. American Association for Marriage and Family Therapy (2017) MFT jobs with the VA, USA.

7. Ouimette P, Vogt D, Wade M, Tirone V, Greenbaum MA, et al. (2011) Perceived barriers to care among veterans health administration patients with posttraumatic stress disorder. Psychol Serv 8: 212-223.

8. Vogt D, Fox AB, Di Leone BA (2014) Mental health beliefs and their relationship with treatment seeking among US OEF/OIF veterans. J Trauma Stress 27: 307-313.

9. Hoge CW, Castro CA, Messer SC, McGurk D, Cotting DI, et al. (2004) Combat duty in Iraq and Afghanistan, mental health problems, and barriers to care. N Engl J Med 351: 13-22.

10. Pietrzak RH, Johnson DC, Goldstein MB, Malley JC, Southwick SM (2009) Perceived stigma and barriers to mental health care utilization among OEF-OIF veterans. Psychiatr Serv 60: 1118-1122. 
Citation: Jones AC, Lucero R (2017) Integrating a Systemic Paradigm When Treating Combat Veterans with PTSD. J Trauma Treat 6: 396. doi: $10.4172 / 2167-1222.1000396$

Page 2 of 2

11. Schwartz R (1994) The internal family systems model. New York: Guilford Press, USA.

12. Green EJ (2008) Individuals in conflict: An internal family systems approach. Family J 16: 125-131.
13. Crane DR, Christenson JD (2012) A summary report of the costeffectiveness of the profession and practice of marriage and family therapy. Contemp Fam Ther 34: 204-216. 